\title{
Management practices and the financial performance of farms
}

Article

Accepted Version

Vanhuyse, F., Bailey, A. and Tranter, R. ORCID:

https://orcid.org/0000-0003-0702-6505 (2021) Management practices and the financial performance of farms. Agricultural Finance Review, 81 (3). pp. 415-429. ISSN 0002-1466 doi: https://doi.org/10.1108/AFR-08-2020-0126 Available at https://centaur.reading.ac.uk/96131/

It is advisable to refer to the publisher's version if you intend to cite from the work. See Guidance on citing.

To link to this article DOI: http://dx.doi.org/10.1108/AFR-08-2020-0126

Publisher: Emerald

All outputs in CentAUR are protected by Intellectual Property Rights law, including copyright law. Copyright and IPR is retained by the creators or other copyright holders. Terms and conditions for use of this material are defined in the End User Agreement.

\section{www.reading.ac.uk/centaur}

\section{CentAUR}

Central Archive at the University of Reading 
Reading's research outputs online 


\title{
Management practices and the financial performance of farms
}

\begin{abstract}
:
Purpose: Farm businesses in England are under pressure to intensify production sustainably while managing costs and meeting market demands. Commodity prices and support from Common Agricultural Policy (CAP) payments are important determinants of profitability. With the United Kingdom (UK) leaving the European Union (EU), revised policy will see farming more exposed to fluctuating commodity prices and financial support from Government more focused on encouraging environmental land management. The research reported here, investigated whether business management practices of farmers influences financial performance, and how policy could be tailored to better meet the needs of farm businesses.

Design/methodology/approach: Regression models were estimated for 862 Cereals, Dairy and Livestock farms in England using official data for 2011/2012, in order to assess whether different farm characteristics, business management practices (identified from a systematic review of 102 studies), knowledge acquisition indicators and manager experience had an effect on four different financial performance ratios. The financial performance of the top $25 \%$ of the sample was also compared to the bottom $25 \%$ in terms of use of business management practices.

Findings: The results show that business planning and benchmarking had a positive, statistically significant, effect on financial performance, as do business size and knowledge acquisition, albeit to a lesser extent. Originality/value: The research reported here is the most extensive examination, to date, of the impact of management practices on the financial performance of farms. Thus, it sends strong policy recommendations.
\end{abstract}

Keywords: management practices, farm financial performance, DuPont Expansion model, strategic planning

Paper type: Research paper 


\section{Introduction}

Farming in England has been under pressure to produce at least similar or higher level of outputs whilst reducing the use of resources and the impact it has on the environment; in short to intensify sustainably, and to do so at the lowest price possible. Alongside this, the historic reforms of the CAP have meant reduced support in recent years for all farm types except for those on upland severely disadvantaged moorland (RPA, 2014 \& 2015 a \& b). With the UK leaving the EU, a revised agricultural policy will see the sector more exposed to fluctuating commodity prices and financial support more focused on environmental land management (Defra, 2018). There is, therefore, a need for farming businesses to professionalise and have tighter control over their production methods and finances.

One way of improving control is to introduce management tools that help track and monitor usage of inputs, including financesinvestment, with the most common tools being cash flow planning, formal business planning and benchmarking ( see, for example, Boddy, 2009; Pettigrew,1992; and Vanhuyse,2016.). These tools can be utilised at various stages of the planning cycle and assist managers to maintain an overview of resources spent and allow them to forecast their future utilisation (Friend \& Zehle, 2009).

Within agriculture in England, the Department for Environment, Food and Rural Affairs (Defra) and the European Commission's Directorate General for Agriculture and Rural Development, as well as Levy Boards and consultancy organisations, have advised and supported farmers implementing management practices for their businesses, as they are of the opinionbelieve that this will improve the management of the farm business, which should, in turn, improve financial performance. Defra (2004a, b \& c) in particular has promoted formal planning and benchmarking as key management tools, and has developed a support package for farm businesses in England, including funding under the Rural Development Programme of the CAP to assist local businesses and farmers to diversify farm activity and boost farm productivity.

On behalf of Government, data is collected and presented on the financial situation of the agricultural industry on an annual basis for policy-making purposes through the Farm Business Survey (Defra, 2020). Despite this, there has been limited financial analysis of farms particularly using tools more commonly associated with the financial industry itself. The $r$ Research on the effect of management practices within the farming industry is also limited. The research undertaken has tendeding to focus on improving efficiency and productivity, excluding any assessment of managerial ability and associated financial 
performance. This makes it unclear whether promoting management practices, or particular tools as a policy $_{2}$ is an approach that farmers and Defra should actively pursue.

The aim of the research summarised here, which stems from Vanhuyse (2016), was to assess whether there are any management practices which farmers should use to improve the financial performance of their businesses. The research question was-expressed as: 'What combination of business management practices has had the largest influence on financial performance for farm businesses in England?'.

\section{Method}

A systematic literature review was initially undertaken to assess the effect of management practices on the financial performance of businesses using the following criteria:

- Types of studies: only those that evaluated the impact of business management practices on financial performance were included;

- Types of interventions: studies that considered the impact of planning, benchmarking and knowledge management were included;

- Geographical spread: studies that considered business management practices and financial performance in Europe, the U.S.A. and Australia were included;

- Publication date: studies published from 1960 to 2015 were included; and

- Sectors: both agricultural and non-agricultural sectors were included.

The review included the terms 'management', 'performance', 'planning' and 'financial performance' and used the databases of journals such as the Journal of Finance, the Journal of Agricultural Economics, the Agricultural Finance Review, the American Journal of Agricultural Economics,_and publishers such as Elsevier, Springer, Wiley-Blackwell, Taylor \& Francis and Google Scholar. All articles were verified and the database was checked for duplicates.

In total, 102 studies were chosen for review, with this previous-research reporting positive results of business planning and benchmarking management practices on financial performance for 74 studies based on the binomial sign test for 4 studies with a negative relationship and 24 studies having no statistically significant relationship ( $z$-score $=7.9259$ meaning significant at the $1 \%$ level)-more frequently than not (see Table 1). For the studies where there was no statistically significant effect ${ }_{L}$ or where the effect was negative, the majority of their researchers concluded that environmental uncertainty and hostility could 
result in planning not having an effect on performance. In unstable environments, managers need to be more flexible, and willing to adapt to change.

Using the findings from the systematic literature review, a research conceptual framework containing six hypotheses was drawn-up:

- H1: Greater use of business management practices leads to better financial performance;

- H2: Knowledge acquisition has a positive effect on financial performance;

- H3: Experience has a positive effect on financial performance;

- H4: Good IT skills have a positive effect on financial performance;

- H5: Farm size has a positive effect on financial performance; and

- H6: Ownership has a positive effect on financial performance.

The systematic review also collected information on how financial performance was defined in the 102 studies (Table 2). In the meta-review by Capon et al. (1990) on 320 studies that looked at factors that influence financial performance, they established that the most frequently used financial performance indicators are: Return on Equity (RoE); Return on Assets (RoA); Return on Sales (RoS); Price/Cost Margin; and Stakeholder Return. These ratios were used by: Plumley \& Hornbaker (1999); Soliman (2004 \& 2008); Erickson et al. (2009); Little et al. (2009); Ahrendsen \& Katchova (2012); andZhang \& Xiaosong (2012); and Pokharel et al. (2019). and make-up part of the DuPont Expansion model. This model was developed in the 1920s to improve the analysis of balance sheets and profit and loss accounts. It breaks down the rate of return on equity for shareholders, and thence the return on assets, into three distinct areas, to include operational or production efficiency or return on sales, asset turnover, and leverage, the extent to which assets are owned by the enterprise (Firer, 1999). Given the perceived importance of productivity (sales) on profitability and the need to manage assets in the farming environment, the research reported here assessed profitability through RoE, RoA, and RoS, and financial efficiency through Asset Turnover (ATO) to determine the overall financial performance. It should be pointed out that, in the USA, RoS is generally called Operating Profit Margin (see, for example, Barry et al., 2000).

These ratios were then calculated and applied to the Farm Business Survey (FBSt dataset for England. Every year, all EU countries have to report on the financial performance of their agricultural industry in an equivalent manner (EC, 2013) and, within England, Rural Business Research, a consortium of six universities and colleges, carries out the FBS. This survey, which has been carried out since 1936 , contains 
information on a farm's financial position as well as information on the farmer, including farmers' age, farm size and whether the farm is owned, rented or held under mixed - tenure. Farm businesses in the FBS are selected stratified by size, farm type and geographical region; spare-time farms are not included but part-time ones are and $7 \%$ of the sample is replaced each year. The FBS is a panel survey and the identitfy of participating farmers is strictly confidential. Their only recompense is that they are able to benchmark their own physical and financial performance against their equivalent peers. Defra (2020) provide further and fuller technical and statistical information on this. Data is obtained by visit from specialist farm accounts investigators.

Additional sections are added to the FBS on an ad-hoc basis, with the 2011/12 dataset containing an additional 'module'_ on the business management practices adopted by the farmers. More specifically, as detailed by Defra (2013) that dataset included information on their use of cash flow planning, formal business planning and benchmarking on the farm, farmers' knowledge of IT and education level, whether he/she participated in a formal Continuing Professional Development (CPD) Scheme, accessed paid business advice, and whether their spouse was engaged in off-farm employment. The latter reflects the idea that these may reflectaffect and influence the management traits of individuals (Dhaouadi, 2014; Gloy \& La Due, 2003)) and their potential to adopt certain practices. In the text and tables that follow, abbreviated descriptions of the business management practices are given and discussed. When the data were collected in the field, participating farmers were provided with full written and verbal descriptions of each practice as Defra (2013) pointed out. For that reason, the 2011/12 dataset for England was selected excluding pigs, poultry and horticulture. This contained data on 862 farms in total: 233 Cereal farms, 228 Dairy farms, 170 Less-Favoured Area Grazing Livestock farms and 231 Lowland Grazing Livestock farms.

To assess the impact of business management practices on financial performance, two tests were carried out. First, a comparison was made between farmers that had businesses that were high financial performers and low performers. For each ratio (RoS, RoA, RoE and ATO), the top 25\% and the bottom $25 \%$ performers were distilled from the dataset per farm type, and the application of each management practice and characteristic was calculated, to ensure that the gap between both groups was large enough to warrant the implementation of a management practice. Then, a comparison between the means of both groups was calculated using t-tests to assess whether there were statistically significant differences related to the management practice and its effect on performance. 
Second, a linear regression model was applied, with the model being:

$$
F P I_{i}=\beta_{0}+\sum_{i j=1}^{K} \beta_{j} x_{i j}+\varepsilon_{i}
$$

Where $F P I_{i}$ is the financial performance indicator (the dependent variable) of farm $\mathrm{i}$ and $F P I_{i} \in\left\{R_{0} S_{i}, R o A_{i}, R o E_{i}, A T O_{i}\right\} ; x_{i j}$ are the explanatory (or independent) variables such as formal business planning, cash flow planning, membership of a CPD scheme, education, farm size, etc.; $\beta_{j}$ are the coefficients to be estimated and $\mathrm{K}$ is the number of coefficients. The errors $\varepsilon_{i}$ are assumed to be normally distributed with variance $\sigma^{2}$. Table 1 gives an overview of the variables used in the regression analysis.

For RoE, RoA and RoS, a multiple linear regression model was estimated using Generalised Least Squares as it did not violate any assumptions. A logarithmic transformation was necessary for ATO, in order to achieve more normally distributed data.

Testing was undertaken to see if the model was specified correctly, including verification of the existence of heteroskedasticity, transformation of variables, omitted variables and correlation of independent variables. The models were estimated in two steps: in a first step, the direct effects were estimated, followed by an estimation of the interaction effects, the application of more than one management practice, in a second step.

\section{Results}

The results of both the t-tests and regression analysis confirm that use of the business management practices considered has a statistically significant, positive effect, on the financial performance of farm businesses in England for the 2011/12 harvest year (Tables $\underline{2} 3$ to $\underline{7} 6$ and 8 and 9 ). However, the reader should be clear that the analysis reported here was based on a single one-year panelcross section data analysis conducted on a dataset that is now eight years old.

In the comparison of the high and low financial performers using the t-test, it is evident that the higher performers consistently apply more cash flow planning, formal planning and benchmarking practices on their farm than the low performers (proving Hypothesis 1 ). Table $2 \underline{3}$ shows the comparison between high and low performances for the ratio RoS, Table $\underline{3} 4$ gives the comparison for ATO, while Tables $\underline{4} 5$ and $\underline{5} 6$ provide the results for RoA and RoE respectively. 
Looking across all four $\underline{\text { Tables } 2-5}$, the results show that formal planning differences between the high and low financial performance groups are statistically significant, at the $5 \%$ level for RoS and at the $1 \%$ level for ATO, RoA and RoE. Regular cash flow planning is also statistically significant for three of the ratios at the $1 \%$ level for RoS and at the $5 \%$ level for RoA and RoE. The difference in the use of benchmarking between the two groups is also statistically significant at the $1 \%$ level for RoS, RoA and RoE. Neither cash flow planning nor benchmarking are statistically significant for ATO. Differences between the low and high financially performing farmers as a result of using a combination of practices was also evident. Most notably using formal planning and benchmarking was statistically significant for RoS at the $1 \%$ level, and for RoE using formal planning and cash flow planning, formal planning and benchmarking, and all three management practices in combination was statistically significant at the $5 \%$ level.

In terms of knowledge acquisition (Hypothesis 2), there is a statistically significant difference in both paying for advice and having a university degree. Low performers were using less paid advice than high performers, statistically significant for RoE at the $1 \%$ level. Low performers also scored less in terms of having a university degree, the latter being statistically significant at the $5 \%$ level for ATO and at the $10 \%$ level for RoA and RoE. Being a member of a CPD Scheme has no statistically significant effect on any ratio; low and high financial performers do not apply this tool differently.

Where experience is concerned (Hypothesis 3), the difference in age is statistically significant at the $1 \%$ level for ATO and RoS and at the 5\% level for RoA and RoE, with high performers being younger than the low performers. There is also a difference in IT skills (Hypothesis 4), with low performers not rating as highly on this indicator as high performers, statistically significant at the $5 \%$ level for RoS, RoA and RoE. The difference in having a working spouse is only statistically significant for ATO at the $5 \%$ level.

Farm size, in area, terms also makes a difference (Hypothesis 5). Low performance farms tend to be smaller than high performance farms, and the difference is statistically significant at the $1 \%$ level for all four business ratios. Finally, the effect of ownership affects the ratios in a different manner. Owner occupiers (Hypothesis 6) outperform mixed-tenure or tenant farmers in terms of RoS, statistically significant at the $10 \%$ level, but perform worse on ATO, RoA and RoE, statistically significant for ATO at the $1 \%$ level, and for RoA and RoE at the $5 \%$ level. 
The regression analysis, carried out as a second examination of whether use of the studied business management practices affects financial performance, confirms some of the above differences. Fable 7 gives an overview of the variables used in the regression analysis. Table 68 shows the results of the regression analysis for the direct effects, and Table $\underline{7} 9$ for the interaction effects, respectively.

The R-squared are 0.3949 for RoS, 0.3141 for log_ATO, 0.1632 for RoA and 0.1979 for RoE. The interaction models were also statistically significant from 0 , but had a lower R-squared, namely 0.2461 for RoS, 0.1538 for ATO, 0.1108 for RoA and 0.0956 for RoE. The interaction effect models explain less of the variation in the dataset than the direct effect models. However, the interaction effects model for RoS has a higher Rsquared than the direct effects model for both RoA and RoE.

Looking at the management practice activities (Hypothesis 1), the direct effects (Table $\underline{6} 8$ ) show different results than the interaction effects (Table $\underline{79}$ ). In terms of direct effects, formal planning, by itself, has a positive, statistically significant effect on log_ATO only. In turn, benchmarking has a positive, statistically significant effect on RoS, but a negative, statistically significant effect on log_ATO. Cash flow planning is not statistically significant for any of the four ratios examined. In terms of interaction effects, carrying out formal planning and cash flow planning has a positive, statistically significant effect on log_ATO, RoA and RoE. Combining formal planning with benchmarking also shows positive, statistically significant effects, this time on RoS, RoA and RoE. These practices are significant at the 5\% level, and impact RoS with $8.54 \%$, RoA with $2.27 \%$ and RoE with $3.10 \%$, meaning these practices affect financial performance quite substantially. Undertaking all three practices does not have a statistically significant effect on any of the financial ratios.

In terms of knowledge acquisition (Hypothesis 2), being a member of a CPD Scheme has a positive, statistically significant effect on RoS, but not on any of the other ratios. The effect is quite large (7.42\%), and is statistically significant at the $5 \%$ level. None of the other knowledge acquisition practices, having a university degree or accessing advice, have a statistically significant effect on the ratios.

Experience (Hypothesis 3), measured in age of farmer, has a minor, negative effect on log ATO (0.68\%) and is statistically significant at the $1 \%$ level. Engaging in off-farm labour, by having a spouse that works elsewhere and gains an additional income, does not have a statistically significant effect on any of the ratios examined. 
Having good IT skills (Hypothesis 4) has no statistically significant effect on any of the four business ratios.

Size, in area, of the farm business has a statistically significant, positive effect on all four ratios, and at the 1\% significance level (Hypothesis 5). This shows that resources, if utilised more effectively through an increase in size, will lead to economies of scale and advantages in financial terms. The effect is the largest for log ATO, which was to be expected as ATO measures how assets are used to generate sales. It is quite substantial for RoS at $10.62 \%$ when increasing from a small to a medium-sized farm, and at $18.28 \%$ when increasing to a large farm. For RoA and RoE, the effects are between $1.55 \%$ and $3.51 \%$, and $2.55 \%$ and $4.32 \%$ when increasing to a medium and large-sized farm respectively.

Ownership matters for RoS, log_ATO and RoE (Hypothesis 6). While ownership has a statistically significant, positive effect on RoS due to the fact that owner-occupiers have a different cost structure than tenant farmers, it has a statistically significant, negative effect on log_ATO and on RoE. The effect of ownership on log_ATO is quite large $(-51.30 \%)$, but this is, in part, because ATO is transformed. For RoE, the effect is small, at $-0.82 \%$, and is statistically significant at the $10 \%$ level only. Ownership is not statistically significant on RoA.

\section{Discussion and conclusions}

Of all the variables examined from the dataset covering both the farm descriptors and the adoption of management practices, the one that had most influence on financial performance in terms of both profitability and financial efficiency was increasing farm size in area terms. This was evident from both the comparison of low and high performers through business ratios using t-tests and in the regression analysis. It is generally believed (see, for example, in the seminal text books of Barry et al. (2000), Nuthall (2010) and Warren (1998), and the research in England of Hadley (2006) and Wilson et al. (2001) and in the USA of Wolf et al. (2016)), and demonstrated in the analysis summarised here, that larger farm businesses can utilise resources more strategically and effectively.

The analysis also demonstrated the importance of farmers undertaking certain management practices, as the results suggest that their adoption can also benefit farm business financial performance. This resonates with work in the USA as reported by Gloy \& La Due (2003) and Plumley \& Hornbaker (1999). Individually, the comparison between the high and low performers represented in the data set 
demonstrated that formal planning, cash flow planning, and benchmarking all have positive effects on profitability, with adoption of more than one of these in combination also having positive effects. This is not, however, clearly evident in terms of financial efficiency. The regression analysis also demonstrates a positive effect for profitability from formal planning and benchmarking, and also when these two are used in combination. A positive effect for both profitability and efficiency is also evident from the regression analysis when cash flow planning is combined with formal planning. This is not evident when using cash flow planning in isolation. What the results show is that it matters to plan and review. This is especially the case when several tools and techniques are combined-together in practice.

Other factors, beyond that of farm size and the adoption of management practices appear to have less, mixed or even a negative influence on financial performance.

Knowledge acquisition appears to have a limited, and mixed, influence on profitability and no effect on financial efficiency in terms of being a member of a formal CPD Scheme, and/or accessing advice. When comparing low and high performers, the results are positive for accessing advice for profitability for only one ratio, and in the regression analysis for a different ratio. There is no evidence that being a member of a CPD Scheme has any influence on profitability. This may be due to the lack of formal opportunities in the farming sector. There may, however, be informal opportunities not captured in the data set used in this analysis. Having a University degree also appears to have a limited influence. When comparing the low and high financial performers, having a degree can have a positive impact on profitability. However, the regression analysis suggests there is no positive impact. The analysis indicates there is no proven benefit in having a degree for financial efficiency.

Experience, as represented by age of farmer, does appear to have a positive impact on both profitability and financial efficiency according to the results from the comparison of low and high performers. The regression analysis, however, does not support this, suggesting that, in fact, experience that comes with age can have a negative influence on financial efficiency. Similarly, having IT skills also appears to have a positive impact on profitability according to the results from the comparison of low and high performers, but again this finding is not supported by the results of the regression analysis.

Engaging in off-farm employment activities in the form of having a working spouse, did not indicate any benefits for profitability, but in the comparison of low and high performers it did have an influence on 
financial efficiency.

Ownership/tenurial status appears to have a negative influence on profitability and financial efficiency. In the comparison of low and high performers ${ }_{-}$and $_{L}$ in the regression analysis, there appears to be a positive benefit for one ratio only. For most of the other profitability ratios and for the financial efficiency ratio the impact is negative. It may be the case that ownership involves incurring debt and thus debt repayments. This could be one factor that would explain the negative influence of ownership on financial performance.

There are some important policy implications that can be drawn as a result of the analysis presented here. However, the reader should consider the fact that the financial performance measures were for one year only and that weather and other factors could have impacted on this. In addition, the management practices survey was conducted for one year only. Thus, causality could not be explored in a definitive way and our analysis only showed association, albeit strong for some of the factors considered. First, the research confirms the findings from the systematic literature review initially carried out. It expands the evidence base on the importance of management practices to improve financial performance, but differentiates between a series of tools, identifying which ones could potentially be most beneficial for farm businesses if their aim is to increase financial performance. The research highlights the importance of formal planning and benchmarking, but the evidence is less convincing for cash flow planning. Nevertheless, it does suggest, in the case of all these three management practices, that a combination of two or more of these would have the largest impact compared to the adoption of one only. Related to this, is the need to understand what these management practices actually constitute.

The dataset used carried with it some limitations, particularly with the definitions used. It is unclear how farmers understand some management tools and skills, for example, what processes are used to set-up the formal plan, and how they utilise benchmarking to compare their situation with that of others. There is also no information on the quality of the business planning instruments reported. Gathering further information on the quality of the tools and their effects could build out the evidence base further in the future as could extending the analysis for a longer period, say three years. This would avoid and smooth the effects of annual fluctuations in vields and financial performance for farm businesses resulting from weather and disease changes.

Second, the research suggests the need for policy makers to adjust policies and programmes to support 
the development of managerial skills. This is especially pertinent for the UK as farmers will have to quickly adapt to the trilogy of challenges they now (Aay November 2020) face from Brexit, COVID-19 and Carbon Net Zero. What is evident from the results is that formal CPD schemes, accessing advice and a University education may not always be a significant positive influence. This suggests the need to rethink the provision of information in relation to management practices and the subsequent processes behind their implementation. Related to this is the role of wider industry and how it can better meet the needs of farmers. Responding to new knowledge is essential in innovating and improving both financial and technical performance. Whilst there is a role for the farmers themselves in this, there is also a role for industry organisations and rural professionals in determining how best for the farming population to acquire knowledge to improve both profitability and financial efficiency of farm businesses. The emphasis should be on designing appropriate mechanisms to encourage the adoption of management practices.

Finally, if financial performance of farm businesses is to be maximised, farmers should try to achieve economies of scale through increasing the size of their business. This may not necessarily be about buying or renting more land, with the data suggesting that ownership, and thus the purchase of land, may actually have a negative effect on financial performance. An alternative approach is through collaboration with other farmers in terms of pooling and sharing resources such as the labour, machinery and fixed capital already invested.

\section{References}

Ahrendsen, B.L. and Katchova, A.L. (2012), "Financial ratio analysis using ARMS data", Agricultural Finance Review, Vol. 72 No. 2, pp. 262-272.

Barry, P.J., Ellinger, P.N., Hopkin, J.A. and Baker, C.B. (2000), Financial management in agriculture, The Dryden Press, Chicago, IL.

Boddy, D. (2009), Management: an Introduction, 4th ed. Pearson Education Limited, Harlow, UK.

Capon, N., Farley, J.U. and Hoenig, S. (1990), "Determinants of financial performance: a meta-analysis", Management Science, Vol. 36 No. 10, pp. 1143-1159. 
Defra (2004a), "Getting started in farm management accounting. Part I: using the farm accounts to point the way", available at: http://adlib.everysite.co.uk/resources/000/015/579/defra_using-accounts1.pdf (accessed 16 November 2015).

Defra (2004b), "Getting started in farm management accounting. Part II: mapping out a farming future", available at http://adlib.everysite.co.uk/resources/000/015/753/defra_accounting2.pdf (accessed 16 November 2015).

Defra (2004c), "Farm business benchmarking. Part II: mapping out a farming future", available at http://adlib.everysite.co.uk/resources/000/220/545/benchmark-online.pdf (accessed 16 November 2015).

Defra (2013), "Business Management Practices on Farm 2011/12, England", available at https://www.gov.uk/government/uploads/system/uploads/attachment data/file/201043/fbsbusinessmanagement-statsnotice-22may13.pdf (accessed 27 October 2020).

Defra (2018), "Health and harmony: the future for food, farming and the environment in a green Brexit", CM 9577, TSO, London, UK.

Defra (2020), "Farm business survey - technical notes and guidance", available at https://www.gov.uk/guidance/farm-business-survey-technical-notes-and-guidance (accessed 27 October 2020).

Dhaouadi, K. (2014), "The influence of top management team traits on corporate financial performance in the US", Canadian Journal of Administrative Sciences- Revue Canadienne des Sciences de l' Administration, Vol. 31 No. 3, pp. 200-213.

Erickson, K.W., Moss, C.B. and Mishra, A.K.A. (2009), "Regional differences in agricultural profitability, government payments, and farmland values: implications of Du Pont expansion", Agricultural Finance Review, Vol. 69 pp. 49-66. 
EC (2013), “Agriculture and Rural Development: FADN", available at:

http://ec.europa.eu/agriculture/rica/index en.cfm (accessed 22 February 2016).

Firer, C. (1999), "Driving financial performance through the DuPont identity: a strategic use of financial analysis", Financial Practice and Education, Vol. 9 pp. 34-46.

Friend, G. and Zehle, S. (2009), Guide to Business Planning, $2^{\text {nd }}$ ed. Profile Books, London, UK.

Gloy, B.A. and LaDue, E.L. (2003), "Financial management practices and farm profitability", Agricultural Finance Review, Vol. 63 No. 2 pp.157-174.

Hadley, D. (2006), "Patterns in technical efficiency and technical change at the farm-level in England and Wales 1982-2002", Journal of Agricultural Economics, Vol. 57 pp. 81-100.

Little, P.L., Little, B.L. and Coffee, D. (2009), "The Du Pont model: evaluating alternative strategies in the retail industry", Academy of Strategic Management Journal, Vol. 8 pp. 71-80.

Nuthall, P.L. (2010), Farm Business Management: the Core Skills, CABI, Wallingford, UK.

Pettigrew, A. (1992), "The character and significance of strategy process research", Strategic Management Journal, Vol. 13 pp. 5-16.

Plumley, G.O. and Hornbaker, R.H. (1999), "Financial management characteristics of successful farm firms", Agricultural Finance Review, Vol. 51 pp. 9-20.

Prasad Pokharel, K., Regmi, M., Featherstone, A.M. and Archer, D.W. (2019), "Examining the financial performance of agricultural cooperatives in the USA", Agricultural Finance Review, Vol. 79 No. 2 pp. 271$\underline{282 .}$ 
Rural Payments Agency (2014), "RPA announces 2014 SPS entitlement values", available at https://www.gov.uk/government/news/rpa-announces-2014-sps-entitlement-values (accessed 16 November 2015).

Rural Payments Agency (2015a), "Basic Payment Scheme entitlement values and National Reserve confirmed", available at https://www.gov.uk/government/news/2015-basic-payment-schemeentitlement-values-and-national-reserve-confirmed (accessed 16 November 2015).

Rural Payments Agency (2015b), "The Basic Payment Scheme in England 2015. Guidance for farmers about the Basic Payment Scheme in 2015", available at https://www.gov.uk/government/uploads/system/uploads/attachment data/file/406452/BPS Handboo

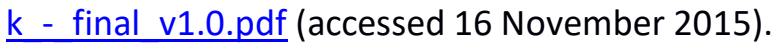

Soliman, M.T. (2004) Using Industry-Adjusted DuPont Analysis to Predict Future Profitability, Stanford University, CA, USA.

Soliman, M.T. (2008) "The Use of DuPont Analysis by Market Participants", The Accounting Review, Vol. 83 No. 3, pp. 823-853.

Vanhuyse, F. (2016), "The impact of management practices on financial performance: evidence from farm businesses in England", unpublished PhD Thesis, University of Reading, Reading, UK.

Warren, M. (1998), Financial Management for Farmers and Rural Managers, $4^{\text {th }}$ ed. Blackwell Science Ltd, Oxford, UK.

Wilson, P., Hadley, D. and Asby, C. (2001), "The influence of management characteristics on the technical efficiency of wheat farmers in eastern England", Agricultural Economics, Vol. 24 No. 3, pp. 329-338.

Wolf, C.A., Stephenson, M.W., Knoblauch, W.A. and Novakovic, A.M. (2016), "Dairy farm financial performance: firm, year and size effects", Agricultural Finance Review, Vol. 76 No. 4, pp. 532-543. 
Zhang, B., and Xiaosong, Z. (2012), "The Application of Adjusted DuPont Model in Financial Performance Evaluation", paper presented at the $7^{\text {th }}$ International Scientific Conference, Business and Management, Vilnius, Lithuania. 